\title{
Temporal Interrelations
}

\begin{abstract}
This chapter investigates temporal interrelations of represented events with an emphasis on dissimilarities among temporal interrelations. Two distinctions that are vital for grasping media differences are highlighted: possible temporal differences between (static or temporal) representing media products and (temporal) narratives, and potential temporal differences within narratives, more precisely between overall narratives and core stories. Particular attention is given to the convention of sequential decoding, which is important for inducing temporality in some forms of static media products. These explorations make it possible to understand both the transmedial possibilities and the media-specific restraints for narration.
\end{abstract}

Keywords Transmedial narration $\bullet$ Narrative time $\bullet$ Media product $\bullet$ Narrative: Story $\bullet$ Sequential decoding

Although the previous chapter was mainly attentive to the nature of represented events and their conceptual relations to existents and states, the last section also started investigating interrelations of events. This chapter will take the step toward examining temporal interrelations of events. In so doing, we move to the central part of the definition of story as represented events that are temporally interrelated in a meaningful way. As the notion of represented events being temporally interrelated is, as such, rather

(C) The Author(s) 2019

L. Elleström, Transmedial Narration, https://doi.org/10.1007/978-3-030-01294-6_7 
unproblematic - it simply means that events can be understood to precede and follow each other in various ways-the discussions will be concentrated on differences among temporal interrelations.

To be able to disentangle the crucial phenomenon of temporal differences in narration in a lucid way, I will repeat the three levels of narration that were first presented in Chap. 3:

- A media product with particular basic media traits and other formative qualities provides certain sensory configurations that are perceived by someone; these sensory configurations come to represent

...

- ... media characteristics forming a complete narrative with all its many specific details and features; furthermore, the perceiver comprehends that this narrative surrounds ...

- ... a scaffolding core, the story, consisting of represented events that are temporally interrelated in a meaningful way.

Inspecting this three-level distinction, one can discern two main ways in which narration can hold vital temporal differences: (1) There may be a difference between the basic temporal features of the media product and the narrative; (2) There may also be a difference situated within the narrative, namely between the complete narrative and the core of the narrative, the story.

These two kinds of temporal differences in narration-on one hand between the media product as representamen and the narrative as object and, on the other hand, within the object; that is, between the complete narrative and the scaffolding core story-are both central to understanding the possibilities, limitations, and particularities of transmedial narration.

\section{Temporal Differences Between Media Products AND Narratives}

Investigating the first kind of temporal difference in narration, between the media product and the narrative, requires a methodical approach grounded especially in the spatiotemporal and semiotic modalities; although the material and sensorial media modes are not irrelevant, of course, there is no call to elaborate on them here beyond what was already done in Chap. 4. 
In communication in general, there are four principal possibilities regarding temporal similarities and differences between a media product and a virtual sphere. There may be temporal media products representing temporal virtual spheres; temporal media products representing static virtual spheres; static media products representing temporal virtual spheres; and static media products representing static virtual spheres. As narratives are temporal virtual spheres, only two main options need to be considered: temporal media products representing temporal virtual spheres (narratives); and static media products representing temporal virtual spheres (narratives). Therefore, the simple initial observation to be made here is that, in principle, both temporal and static media products might represent temporal virtual spheres such as narratives. Moreover, it is fairly generally accepted that this is also the case in practice, as will be illuminated here in some detail.

A methodical overview of the abundance of intricate ways to narrate can begin with some comments on temporal media products forming narratives. In the simplest of cases, sensory configurations that are each understood to represent some event evolve one after another in the temporally unfolding media product. The default result of such an actual temporal sequence of representations, conditioned by the temporal progression of the media product, is that the temporal sequence of the media product corresponds to a temporal sequence in the virtual sphere. In these elementary cases, there is a strong parallelism between the temporal qualities of the media product and the narrative.

If one listened to the radio, for instance, and heard first a scream, then a bang, and finally the sound of something heavy falling to the ground, one would normally (unless other things speak against it) take those sounds to iconically represent a virtual sphere where something like this happens: first, someone sees a person with a gun and screams, then the gun is fired, and finally a body falls to the ground because it has been hit. The order of and the intervals between the sounds and the represented events would be understood to match each other (again as long as more complicated interpretations are not motivated). In instances like this, the narration is so straightforward that the distinctions between temporalities in media product, narrative, and story cannot be practically effectuated.

However, adding further details to the representation of these three events could lead to the construction of a more complex narrative. For instance, the actual narratee may perceive that in the virtual sphere there is a long temporal gap between the scream and the bang, or that the 
scream was in fact heard after the bang and the heavy fall. Temporal media types may indeed accomplish intricate narratives. The point is that temporal media products ultimately require very little, except their very temporality, to be capable of simple narration. The matching temporalities of temporal media products and temporal virtual spheres plainly facilitate narration.

The temporal difference between static media products and temporal virtual spheres requires more sophisticated conditions to make narration possible. I discern three main ways to bridge such a temporal difference and compensate for the lack of temporality in static media products. In practice, these conditions may be present separately or simultaneously.

The first prerequisite is a convention of sequential decoding. Such conventions, or strong habits, form the ground of a symbolic element also in those media types that are rather dominated by icons or indices. They can make static media products appear almost as if they were temporal, which means that their sequentiality may, by default, be understood to correspond to a temporal sequence in the virtual sphere. Some basic examples are regulated sequential decoding of iconic media types (such as series of still images), sequential decoding of iconic and indexical media types (like a succession of photographic still images), and sequential decoding of symbolic media types (with written verbal texts as the principal but not exclusive example). It is precisely the strong convention of sequential decoding that makes writing appear so similar to speech despite the fundamental difference between a static and a temporal media type.

The second prerequisite is the representation of temporal positions or relations. Icons may represent objects working as indices for temporal positions: clocks, the positions of the sun in the sky, objects connected to specific seasons of the year (snow, blossoming cherry trees, falling leaves, etc.), certain holidays, and so on. One example is visual two-dimensional still images that represent numerous hour-glasses indicating different time positions for several depicted events. Another example is tactile threedimensional reliefs that iconically represent the growth of an infant through the development of bodily age characteristics connected to a number of crucial life events. Words or other symbols may represent temporal positions ('in the afternoon', 'Tuesday', '1984') or temporal relations ('earlier', 'first', 'now', 'then', 'later'). A visual, verbal, and two-dimensional text may represent a series of events temporally anchored to specific months of the year, or a tactile, verbal three-dimensional braille text may represent events that are bound together through different 
phases of the moon. All these devices may certainly occur also in temporal media types.

The third prerequisite is representation of objects that make it possible to create a temporal virtual sphere through inferences about past and future time. This is achievable because of collateral experience. As there are several forms of collateral experience, there are several means of achieving represented temporality through inferences about past and future time. Collateral experience in the form of general knowledge of both the natural and the cultural world often incites one to draw inferences of what has probably happened before and what will probably happen after a single event represented by a static media product. Any form of representation of, say, someone jumping from a bridge will normally lead to the perceiver inferring a temporal continuation: the person will fall down until something or someone rescues her or until she hits the ground or water underneath. This is what one's knowledge of the physical laws contributes. By the same token, the perceiver is likely to infer that something vital has anticipated the act of jumping: the single represented event cannot stand entirely alone, one presumes, for the simple reason that this is not how things work in the world that we are familiar with. So, the virtual sphere represented by the static media product may grow to include preceding events, such as the person having been forced by someone else to jump, having experienced a serious trauma that makes life unbearable, or having taken some heavy mind-altering drug. This is what one infers because of one's knowledge of human nature and culture.

As discussed above, general knowledge of the world may be developed to cognitive schemata, which means that inferences like these can be rather extensive. Any static media type representing an average person debarking a commercial airplane will open up for inclusion of a whole cognitive schema in the virtual sphere: the person has bought a ticket, then gone to the airport, passed security control, embarked, and spent some time sitting down in the aircraft before debarking, which will be followed-our cognitive schema tells us - by other standard procedures for airport arrival. In some cases, then, extensive cognitive schemata may provide static media products with the complete material for forming narratives.

Furthermore, collateral experience in the form of specific knowledge of already narrated stories may deliver additional events to the virtual spheres of static media products. If we are confronted with the representation of a little girl wearing a red hood and meeting a wolf in the woods, it may be almost unavoidable to see this event as part of a well-known story-given 
that the actual communicatee is familiar with the story, of course. The succession of events unfolds in the mind of the perceiver, creating a virtual sphere that is similar to those virtual spheres that have been formed in earlier perceptions of the story. Naturally, all forms of collateral experience are also relevant for temporal media types, although they are not always as urgent for achieving narration.

All these distinctions and elaborations not only contribute to our understanding of how static media types may narrate at all but also help us appreciate the balance between similarities and differences amid narration in temporal and static media types, respectively. They are, in brief, central for understanding the possibilities and limitations of transmedial narration.

\section{Temporal Differences Between Narratives}

\section{AND STORIES}

We have seen that the temporality of the overarching narrative may be represented by either a temporal or a static media product. In the latter case, there is a temporal difference between the media product and the narrative; this is the first kind of temporal difference in narration. The second kind of possible temporal difference in narration is a difference situated within the narrative, namely between the temporality of the complete narrative and the temporality of the scaffolding core of the narrative, the story. It should be remembered, though, that it is not always possible to firmly establish the distinction between narrative and story in actual narratives, and that it only sometimes involves a temporal difference.

Why is it, then, that stories are sometimes construed in such a way that a temporal difference between the complete narrative, being more complex and elaborated, and the core story, consisting of the essence of temporal events in the narrative, is established? It is probably mainly because of an urge to think in terms of how the temporally interrelated events in the narrative would unfold if they would appear in directly perceived real life instead of being represented. Having a drive to understand what really happens around us is essential for our survival, and this includes a will to comprehend the ways in which events are interrelated.

In the case of temporal media types and static media types that are sequentially decoded because of conventions, the temporal qualities of the represented events in the overall narrative are, if not determined, at least 
strongly directed by the temporality or sequentiality of the media product. This is why the interrelations among events in the narrative may be deranged, so to speak, compared to how they would unfold if they were directly perceived in real life. Depending on what the actual narrator wants to emphasize, a story about someone who sees a person with a gun and screams, after which the gun is fired and a body falls to the ground, can be enwrapped in various forms of narratives emphasizing certain events rather than others, certain states rather than events, or certain interrelations among states and events. An efficient means of achieving such emphasis may be to manipulate the temporal interrelations of the story, thus forming narratives about, say, the state of the screaming person after the shot compared to the state before the shot, the dramatic event of the shooting, or the relation between the preceding state of the shooting person and the act of shooting. In general, an actual narrator may attract attention by starting with the most sensational event or create suspense by way of withholding it. She may also want to narrate a chain of events in the order she learnt about the separate events rather than in the order they possibly actually happened, thus emphasizing her own experience of putting the events together, which naturally creates a temporal difference between narrative and story.

In the case of media types not being temporal or sequentially decoded because of conventions, the order in which the represented events are encountered cannot, for obvious reasons, be determined by the (lack of) temporality and conventional sequentiality of the media product. This is not to say that the perceiver randomly explores the spatially represented events in the narrative. Some sensory configurations may be presented (through size or position, for instance) so that they are distinguished as more salient than others, which can lead to a rudimentary order of perception and partly decide the relative duration of certain perceptions. In museums, for instance, the visitor can even be directed by walls and other physical obstacles to follow a certain path and hence encounter represented events in an arranged order. Anyhow, the absent or relatively weak determination of how static but spatial media products are sensorially perceived in time weakens the possibility of construing a difference between the temporality of a narrative and the temporality of a core story. Perceivers of static media products that are not conventionally decoded sequentially presumably have little incentive to first construe an order of events in the narrative, with all its many specific details and features, and then discern another order of events in the core story; such a differentiation would be 
a detour for a perceiving mind striving to get a grip of what happens in the virtual sphere.

Thus, the exploration of temporal differences between narratives and stories is most, but certainly not exclusively, relevant for narration involving temporal media products and media products that are conventionally decoded sequentially. However, temporal differences between narratives and stories include more than differences of order and those other differences can be applied more broadly transmedially. Here I follow Gérard Genette, who has suggested three different sorts of temporal divergences in narratives regarding order, duration, and frequency (Genette 1980 [1972]: 33-160; the possible difference between the order of events in the 'plot' and the 'story' was already established in Tomashevsky 2012 [1925]: 67). Adopting and adapting this to a transmedial perspective, I suggest that there may be differences in the temporal order, duration, and frequency of represented events between the complete narrative and the core story. In other words, a difference may be perceived between how the order, duration, and frequency of events and states are represented in the narrative and how we assume that the order, duration, and frequency of events and states would appear in real life, not being represented. Therefore, construing a story may involve both a concentration and a rearrangement of represented events.

Let me briefly illustrate the idea of temporal differences with the aid of the example of listening to the radio and hearing first a scream, then a bang, and finally the sound of something heavy falling to the ground. As we have already noted, these sounds can be taken to represent the events of a narrative of someone seeing a person with a gun and screaming, after which the gun is fired and a body falls to the ground because it has been hit. Given the sparse sensory configurations transmitted by the radio, this is not the only possible narrative that may be construed. The point here is that if one reduces this narrative to a story, taking away a few marginal details, virtually the same order, duration, and frequency of events will remain.

However, such a correspondence is not necessarily the case in narration. Presume that one instead hears a bang, followed by a long pause. After that, an exceedingly, unnaturally long scream followed by a bang is heard and this sequence is repeated three times. Finally, after yet another long pause, the sound of something heavy falling to the ground is heard. Such an auditory, temporal, and iconic media product may well be understood as an artistic realization of the same simple story consisting of three 
interrelated events: a scream followed by a bang followed by a fall. In this case, however, there are substantial temporal differences between narrative (the temporal qualities of which are no doubt strongly directed by the temporal qualities of the media product) and story. The order differs because the narrative starts with the shot instead of the scream. The duration differs because the scream and the pause between bang and fall are longer in the narrative than in the story. The frequency differs because both the single scream and the single bang in the story are repeatedly represented in the narrative.

Narratology has long explored these forms of temporal differences, so it should suffice here to add that there may be temporal differences between overarching and embedded narratives and among separate embedded narratives that seem to have a common core and are possibly based on the same story. These narrative interrelations can no doubt be infinitely complicated.

The distinction between temporal qualities of the media product and the narrative, as well as the distinction between temporal qualities of the narrative and the story, are both central to understanding the possibilities and limitations of transmedial narration. Furthermore, the division between the two distinctions, which has a tendency to be blurred, allows for a more fine-grained understanding of temporal similarities and differences in narration. The distinction between temporal qualities of the media product and temporal qualities of the narrative is fundamental for exploring the basic narrative capacities of dissimilar media types. The distinction between temporal qualities of the narrative and temporal qualities of the story is widely recognized for highlighting vital narrative devices. However, this distinction has a limited transmedial reach: it is mainly applicable to temporal media types and media types that are conventionally decoded sequentially.

\section{REFERENCES}

Genette, Gérard. 1980 [1972]. Narrative Discourse: An Essay in Method. Translated by Jane E. Lewin. Ithaca, NY: Cornell University Press.

Tomashevsky, Boris. 2012 [1925]. Thematics. In Russian Formalist Criticism: Four Essays, trans. and ed. Lee T. Lemon and Marion J. Reis, 2nd ed., 61-95. Lincoln and London: University of Nebraska Press. 
Open Access This chapter is licensed under the terms of the Creative Commons Attribution 4.0 International License (http://creativecommons.org/licenses/ by $/ 4.0 /)$, which permits use, sharing, adaptation, distribution and reproduction in any medium or format, as long as you give appropriate credit to the original author(s) and the source, provide a link to the Creative Commons licence and indicate if changes were made.

The images or other third party material in this chapter are included in the chapter's Creative Commons licence, unless indicated otherwise in a credit line to the material. If material is not included in the chapter's Creative Commons licence and your intended use is not permitted by statutory regulation or exceeds the permitted use, you will need to obtain permission directly from the copyright holder.

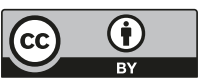

